\title{
Dental Research and

\section{Application of IARTI and Ameliorating Principles to Improve Compliance and Completion of Treatment in General Dental Practice}

\section{Louis ZG Touyz ${ }^{1 *}$ and Leonardo M Nassani ${ }^{1}$}

Affiliation: ${ }^{1}$ Faculty of Dentistry, McGill University, Canada

*Corresponding author: Louis ZG Touyz, Faculty of Dentistry, McGill University, Canada, Tel: 514-398-7203,

E-mail: touyzlouis@gmail.com

Citation: Touyz LZG and Nassani LM. Application of IARTI and ameliorating principles to improve compliance and completion of treatment in general dental practice (2021) Dental Res Manag 5: 23-25.

Received: May 18, 2021

Accepted: Jun 21, 2021

Published: Jun 28, 2021

Copyright: $\odot 2021$ Touyz LZG, et al., This is an open-access article distributed under the terms of the Creative Commons Attribution License, which permits unrestricted use, distribution, and reproduction in any medium, provided the original author and source are credited.

\begin{abstract}
Introduction: Many General Dental Practitioners run single handedly a mini-hospital. Practice administration, delivery of treatment and financial stewardship are all demanding with consequent induction of uncertainty, distress, and diminished performance, loss of satisfaction and unwelcome depression and anxiety. Aim: This contribution describes moderation of stresses in general dental practice by applying amelioration policies. Discussion: This advisory is targeted at all dentists involved in extensive dental therapy. The stress and anxiety of practice management is improved by applying newly established principles of practice, namely the Initial Assessment and Ranking of Treatment Index (IARTI) and What arrangements Have you made to meet your Oligations (WAHUM TOMYO), Immediate Payment Therapy (IPP) and Big Toe Philosophy (BTP). Conclusion: By applying these fundamental principles into general dental practice, much anxiety is relieved, challenges and problems are avoided or resolved and successful practice of dentistry is realized. A much higher frequency of failures will occur if these principles are not applied. Success does depend on applying IARTI and WAHUM TOMYO, IPP and BTP.

Keywords: Anxiety, Compliance, Distress, Finance, Management, Practice, Administration, Community Periodontal Index Treatment Number (CPITN), Initial assessment ranking of treatment index, Periodontal score recording.

Abbreviations: GDP-General Dental Practitioner, IARTI-Initial Assessment and Ranking of Treatment Index, WAHUM TOMYO-What Arrangements Have You Made To Meet Your Obligations?, IPP-Immediate Payment Practice, BTP-Big Toe Philosophy, PSR-Periodontal Score Recording

\section{Introduction and Provenance}

Many General Dental Practitioners (GDPs) enter into providing a Dentistry-Community service with every noble intention gleaned from years of professional training. Attitudes knowledge and skills are honed into focus, to deliver all the services demanded. Ranging from public relations to major invasive oro-facial surgeries, other services called for include:- Office supervision, examination techniques, radiography, conservative and prophylactic therapies,-restorative treatments, pain-control, osseointegrated implants, orthodontics, periodontics, dento-alveolar and maxillo-facial surgery. Essentially contemporary dentists run single handedly a mini-hospital. These services with practice administration, delivery of treatment and financial stewardship become all demanding, with consequent induction of unwelcome, unwanted, unavoidable, uncertainty and distress. Although one major influencing factor for non-compliance with treatment plans is the complexity of treatment, the real reasons for non-compliance remains obscure [1-4]. Some improvement of compliance manifests when patients are continually reminded about appointments, after they initiate therapy [5]. Yet reports about providing dentists on how to avoid potential drop-outs and future noncompliance before initiating therapy are scant. The resultant waste of time effort diminished performance, loss of satisfaction and unwelcome depression and anxiety affects the GDP's ability to successfully serve their communities. This advisory is targeted at

general dental practitioners, oro-dental specialists and admissions officers for extensive dental therapy.

Aim: This contribution describes some simple approaches to ameliorate and positively moderate the stresses in general dental practice.

"Principles dictate policy" Touyz 1962. Stresses can be induced by factors external to Dental Practice. Distress deriving from stress and from various social activities encountered in living has been ranked in the Holmes-Rahestress inventory [also known as the Social Readjustment Rating Scale (SRRS)] on a scale of 0 to 100. An example of the first 10 events is summarized below (Table 1) [6].

Yet, major among the causes of stress to dentists, or to institutions delivering oro-dental therapy, is the poor, sometimes disastrous, selection of patients admitted into therapy at the practice. After over fifty years of teaching, supervision and practice, spread between two academic dental training schools (The Witwatersrand Oral and Dental Hospital Johannesburg South Africa, and the McGill Dental Faculty, Montreal Canada) among the major sources of anxiety arising for oral health care workers, was patient non-compliance and drop-out of planned therapy.
\end{abstract}

Citation: Touyz LZG and Nassani LM. Application of IARTI and ameliorating principles to improve compliance and completion of treatment in general dental practice (2021) Dental Res Manag 5: 2325. 


\begin{tabular}{|c|c|}
\hline Life Event & Mean Value \\
\hline Death of spouse & 100 \\
\hline Divorce & 73 \\
\hline Marital separation from mate & 65 \\
\hline Detention in jail or other institution & 63 \\
\hline Death of a close family member & 63 \\
\hline Major personal injury or illness & 53 \\
\hline Marriage & 50 \\
\hline Being fired at work & 47 \\
\hline Marital reconciliation with mate & 45 \\
\hline Retirement from work & 45 \\
\hline
\end{tabular}

Table1: Social Activity Stress Scale 0-100. The higher the score the more social adjustment demanded.

It remains a fact that:

Patients who don't want to keep their teeth: These people are usually impeded by a meme that coerces them to remove their teeth and replace their chewing with full upper and lower dentures. They are not interested in retaining natural dentition. Frequently they are influenced by cultural norm that doesn't teach oral hygiene, have a complete disinterest in adopting oral hygiene practices, and only want to have a complete dental clearance by extraction of all teeth, and as quickly as possible. This is their final panacea for dental problems. Patient education in this situation can induce anxiety and necessitates more chair side time to explain. These patients are not suitable nor are ready for any advanced restorative or gum therapy.

Of necessity dental treatment demands multiple attendances: A course of planned treatment will clearly indicate to the dentist, and accordingly also the patient, that attendances will need many appointments, extended over a period of time. It is not unusual for treatment plans to first stabilize soft tissues, and then embark on restoring decay, after which major reparative prosthetic work is necessitated. This also applies to orthodontics on children and adults. Consequently multiple attendances are required. Missed appointments waste time, money and effort from a running practice while blocking time slots for potential committed patients. Patients who are not willing to attend reliably, consistently and punctually are a huge source of irritation. Some people just never understand the discipline needed to run a practice, and even become resentful when told they will be charged for missing an appointment. Many think of dentistry as a personal service only to be used on demand when a toothache is felt. If a patient is unwilling to co-operate and attend regularly for optimizing therapy, these patients are not suitable nor are ready for general dentistry or any advanced restorative or gum therapy.

Clients don't want to pay, or don't have resources to pay: This situation is a major source of uneasiness, trouble, and stress. Spectacular dentistry, demands and commands spectacular fees. Patients rarely can easily afford payments, and, unless they have made arrangements to pay, either by insurance, securing loans, or making arrangements with treating dentist, these people turn out to be unreliable, and often fee-dodgers. Those patients who do not want to know in advance what treatments are needed, proposed, or the costs incurred, can only be a source of future trouble, be delinquent in payment and try to maliciously exploit goodwill and gullibility of vulnerable dentists. These patients are not suitable nor are ready for any advanced restorative or gum therapy.

From the above, it is essential to recall some principles referral to: The IARTI, PSR and CPITN: The Initial Assessment and Ranking of Periodontal Treatment Index is an Improved Rapid Classifying Index of Periodontal and Perio-Restorative Cases, which includes data derived from the PSR and CPITN. This IARTI asks three major questions: [7-9]

(i) Do you want to keep your teeth?

(ii) Are you prepared to present at least 10 times?

(iii) Can you afford the costs?

In addition, the IARTI is performed using the WHO probe with tinetip pressure of 15-25 grams. Probing depths are correlated to the pocket measurement to determine a code of the patient, to be able to locate appropriate treatment modalities, its' clinical ranking and progression. The appropriate designated code and likely treatment according to measurement depths of the probe are indicated in Figure 1.

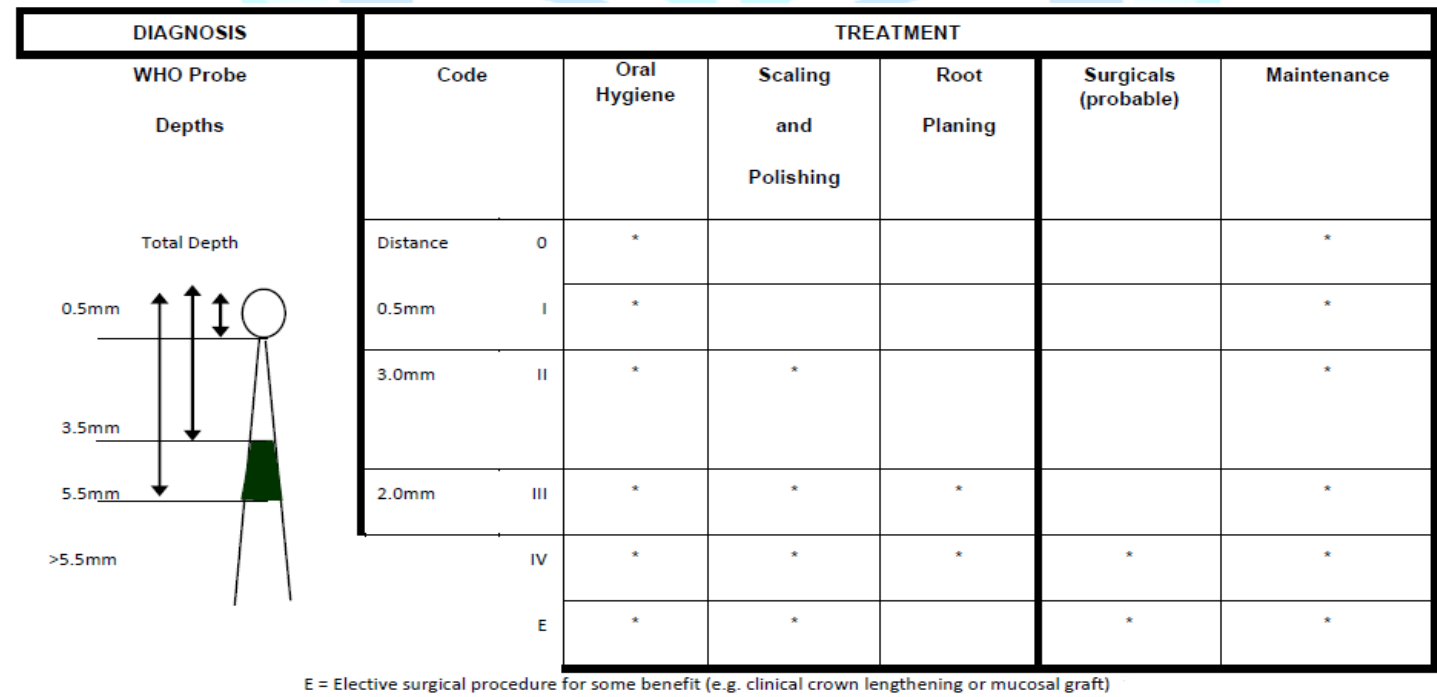

Figure 1: Initial assessment of periodontal disease and probable treatments.

- Coping strategies: Three initial fundamental principles evolve from this: [4]

(i) WAHUM TOMYO: What Arrangements Have You Made To Meet Your Obligations?

(ii) IPP: Immediate Payment Practice

(iii) BTP: Big Toe Philosophy

\section{Discussion}

Successful perio-prosthetic therapy depends on patients returning many times, not only for direct therapy on the gums and teeth, but also for monitoring and maintenance for sustained oro-dental health $[7,10-$ 13].

Citation: Touyz LZG and Nassani LM. Application of IARTI and ameliorating principles to improve compliance and completion of treatment in general dental practice (2021) Dental Res Manag 5: 23-25. 
There are enough stressors which may affect any dentist in practice, which is why reducing the stressors in practice becomes essential. A complete trilogy of positive responses (yes, yes, yes to all questions) of the IARTI is essential before proceeding with treatment. Just using the PSR or CPITN alone, does not provide socio-economic or motivational insights from the patient. Sooner than later these indices (CPITN and PSR) precipitate a disaster, discontinuance, and failure of treatments, either due to lack of compliance, understanding disconnection, or finances. In multiple anecdotal reports from students, directors and clinical controllers and admissions officers, the IARTI has avoided problems, misadventures, and unpleasantness. Many a disaster was voided by rigidly applying this IARTI index in the initial admissions clinics and appointments. Punctuality is the mutual compliment and respect shown to Dentist and Patient.

After a successful IARTI has been established, it is essential for dentists to apply the next set of anxiety relieving principles. "WAHUM TOMYO. [What Arrangements Have You Made To Meet Your Obligations?]" is a direct extension from the IARTI (Figure 2).

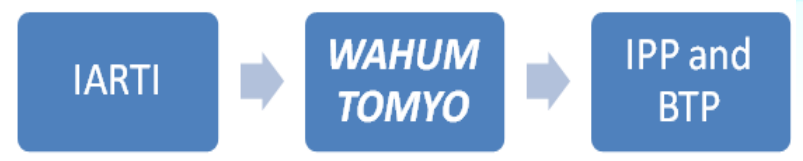

Figure 2: Sequence of stress reducing treatment discussion.

Serious patients accept the full responsibility for payment of impending therapy. An open, honest discussion of payment arrangement clears the air, expectations are clarified and assumptions are assuaged. Assumption is the mother of all foul-ups, and it is mandatory to spell out in writing a Treatment Plan, treatment sequence, number of appointments, and the costs anticipated including how the payments will be made. Clear explanation of Immediate Payment Practice (IPP) and the BTP (Big Toe Philosophy) is essential for the patient to understand. IPP and BTP are direct applications of principles which ensure satisfactory liquidation of fees for work done. Some philosophical pundits insist that demand a "deposit" for proposed work is unethical or immoral, as this may affect the quality of delivery of clinically acceptable services. Accordingly applying IPP and BTP eliminates the stress of paying and restores the rectitude of any spurious implication about pre-payments of treatment.

\section{Concluding remarks}

Principles dictate policy, and this applies to the GDP's Clinical practice. Dentists are not financial Institutions, Money lenders, or Credit Unions. Just keeping a clinic open, disinfected, staffed, and properly equipped, costs the professional a lot of capitol layout and incurs ongoing expenses for rent, staff, equipment power and insurances. GDP's make their living by providing a professional community dental service for the collective health of their communities served. They deserve to be rewarded to sustain their practices and successfully take care of their patient's oral health.

Stress and anxiety of practice management is improved by linking and applying newly established principles of practice, namely the Initial Assessment and Ranking of Treatment Index [IARTI] and What Arrangements Have You Made To Meet Your Obligations (WAHUM TOMYO), Immediate Payment Practice (IPP) and Big Toe Philosophy (BTP). [7-9]. BTP implies that as soon as a patient exits from the dental chair, and their BIG Toe touches the ground....BTP applies, which means, the fee for the completed procedure is payable immediately. Different approaches to ensure compliance have been tried [10]. Successful treatment devolves on the communication between the patient and health-care-provider, and optimizing outcomes depends on the information the health-care-provider procures initially [11].
By assessing the patient and then asking leading questions, patients get involved with the process of treatment planning and subsequently most will ensure satisfactory compliance [11-13]. The advisory as laid out above reinforces the success of these insights.

\section{Conclusion}

By applying these fundamental principles into general dental practice, much anxiety is relieved, challenges and problems are avoided, and successful practice of dentistry is realized.

\section{References}

1. Demirel K and Efeodlu A. Retrospective evaluation of patient compliance and supportive periodontal treatment (1995) J Nihon Univ Sch Dent 3: 131-137. https://doi.org/10.2334/josnusd1959.37.131

2. Perril-Jones $\mathrm{C}$ and Ireland RS. What factors influence patient compliance with supportive periodontal therapy in a general dental practice? (2016) British Dent J 221: 701-704.

https://doi.org/10.1038/sj.bdj.2016.904

3. Umaki TM, Umaki MR and Cobb CM. The psychology of patient compliance: a focused reviews of the literature (2012) J Periodontol 83: 395-400.

https://doi.org/10.1902/jop.2011.110344

4. Checchi L, Felliccioni GA, Gcttto MRA and Kelescian L. Patient compliance with maintenance therapy in un Italian periodontal practice (1994) J Clin Periodontol 21: 309-312. https://doi.org/10.1111/j.1600-051x.1994.tb00718.x

5. Carvalho VF, Okuda OS, Bernado CC, Pannuti CM Georgetti MAP, et al. Compliance improvement in Periodontal maintenance ((2010)) J Appl Oral Sci 18: 215-219. https://doi.org/10.1590/s1678-77572010000300003

6. Holmes TH and Rahe RH. The social readjustment rating scale (1967) J Psychosom Res 11: 213-221. https://doi.org/10.1016/0022-3999(67)90010-4

7. Touyz LZG. Management and coping strategies of stress in dentistry (2015) Dental Res Manag 1: 9-15. https://doi.org/10.33805/2572-6978.103

8. Touyz LZG. Stress and Coping strategies in dentistry (2015) J Depress Anxiety S3: 003. http://dx.doi.org/0.4172/21671044.S3-003

9. Touyz LZG. The IARTI, PSR and CPITN; The Initial assessment and ranking of periodontal treatment index, an improved rapid classifying index of periodontal and periorestorative cases (2015) Dent Health Curr Res 1: 1 http://dx.doi.org/10.4172/2470-0886.1000e102

10. Macri D. Strategies for improving patient compliance (2015) Dimen Den Hyg 5: 30-39.

11. Rozier RG, Horowitz AM and Podschun G. Dentist-patient communication techniques used in the United States: the results of a national survey (2011) J Am Dent Assoc 142: 518-530. https://doi.org/10.14219/jada.archive.2011.0222

12. Ojima M, Hanioka T and Shizukuishi S. Survival analysis for degree of compliance with supportive periodontal therapy (2001) J Clin Periodontol 28: 1091-1095. https://doi.org/10.1034/j.1600-051x.2001.281202.x

13. Dy SM and Purnell TS. Key concepts relevant to quality of complex and shared decision-making in health care: A literature review (2012) Soc Sci Med 74: 582-587. https://doi.org/10.1016/j.socscimed.2011.11.015 